\title{
Las metacaspasas y su rol en la vida y muerte de los parásitos protozoarios humanos
}

\author{
Iveth J. González \\ Departamento de Bioquímica, Universidad de Lausana, Epalinges, Suiza.
}

\begin{abstract}
Las metacaspasas son proteasas de cisteína similares estructuralmente a las caspasas y cuyos genes están presentes en organismos carentes de caspasas, tales como plantas, levaduras y parásitos protozoarios.

El bien conocido papel de varias caspasas en la apoptosis de células de mamíferos, ha motivado el estudio del posible rol de las metacaspasas en la muerte celular programada de los organismos en los cuales se expresan. Así, por ejemplo, las metacaspasas de los parásitos protozoarios humanos de los géneros Trypanosoma y Leishmania han sido implicadas en muerte celular programada. Sin embargo, algunos estudios en $T$. brucei señalan que estas proteínas podrían estar involucradas en otras funciones biológicas tales como procesos de reciclaje. Los parásitos del género Plasmodium también expresan metacaspasas, pero aún se sabe poco sobre su función.

La presencia de más de una metacaspasa en algunos de estos microorganismos, ha llevado a especular que estas proteínas podrían tener funciones fisiológicamente redundantes o diferentes de acuerdo con su localización e interacción con otras moléculas. Los estudios recientes han demostrado que la especificidad catalítica de las metacaspasas difiere de aquélla de las caspasas. Esta característica, sumada a la ausencia de sus genes codificadores en el genoma de mamíferos, hace de las metacaspasas y de sus mecanismos de activación un área interesante de investigación en la identificación de nuevos blancos terapéuticos en los parásitos causantes de tripanosomiasis, leishmaniasis y malaria.

La presente revisión resume la información disponible sobre las metacaspasas y busca motivar la generación de masa crítica en este tema en los países hispanohablantes.
\end{abstract}

Palabras clave: caspasa, apoptosis, Plasmodium, Leishmania, Trypanosoma, malaria.

Metacaspases and their role in the life cycle of human protozoan parasites

Metacaspases are caspase-related cysteine-proteases that are present in organisms devoid of caspases such as plants, yeast, and protozoan parasites. Since caspases are important effector molecules in mammalian apoptosis, the possible role of metacaspases in programmed cell death has been evaluated in the organisms where they are expressed. In some species of the human protozoan parasites Trypanosoma spp. and Leishmania spp., metacaspases have been involved in programmed cell death, although a role of metacaspases in recycling processes in $T$. brucei has also been suggested. Metacaspases are also expressed in Plasmodium spp., however their role in these organisms is still unknown. More than one metacaspase gene is present in some of these parasites, which suggests that these proteins are physiologically redundant or have different functions depending on their localization and protein interactions. The catalytic activity of metacaspases is different from that of caspases-again noting that metacaspase genes are absent in mammals. These characteristics make metacaspases and their activating mechanisms interesting subjects of research in the development of new drug targets for the treatment of trypanosomiasis, leishmaniasis, and malaria. A summary of the literature on metacaspases is provided, and Latin American researchers are encouraged to more actively explore the metacaspase potential.

Key words: caspases, apoptosis, Plasmodium, Leishmania, Trypanosoma, malaria. 
Las metacaspasas son un grupo de proteínas recientemente identificadas, similares a las caspasas (1). Las caspasas son una familia de proteasas de cisteína específicas de aspartato, importantes en los procesos inflamatorios y en el tipo de muerte celular programada, llamada apoptosis de células de mamíferos (2). Se caracterizan por ser expresadas como cimógenos catalíticamente inactivos y requerir de la escisión específica de sus subunidades p20 y p10, por sí mismas (autoprocesamiento de las caspasas iniciadoras) o por otras caspasas (caspasas efectoras) para polimerizarse y alcanzar su máxima actividad enzimática (3).

En la apoptosis, las caspasas son activadas tanto en la vía intrínseca como en la vía extrínseca de inducción de muerte celular.

En la vía intrínseca, en la cual la apoptosis puede ser inducida, entre otros factores, por estrés ambiental o por la ausencia de factores de crecimiento, se produce la liberación del citocromo $\mathrm{C}$ de la mitocondria, el cual, al interactuar con el factor 1 activador de proteasa apoptótica o APAF1, estimula la formación del apoptosoma y la posterior activación de la caspasa iniciadora, caspasa 9.

En la vía extrínseca, en la cual la apoptosis se inicia a partir de la interacción de un ligando extracelular con su respectivo receptor de superficie celular perteneciente a la superfamilia del factor de necrosis tumoral (FNT), se produce el reclutamiento de factores citosólicos para la formación del complejo de señalización inductor de muerte, o DISC (death-inducing signaling complex), y posterior activación de la caspasa iniciadora, caspasa 8 (4). Las caspasas 9 y 8 activadas inician la cascada de activación de las caspasas efectoras 3,6 y 7 , las cuales cortan sus substratos y producen las características clásicas de la apoptosis.

Correspondencia:

Iveth J. González, 3 avenue de l'avant-poste, 1005 Lausanne, Suisse.

Teléfono: (+4121) 3119687

ivethgon@hotmail.com

Recibido: 08/07/08; aceptado:02/04/09
Las caspasas y sus proteínas homólogas han sido descritas en especies tan diversas como el nemátodo Caenorhabditis elegans (5) y el díptero Drosophila melanogaster (6) y son esenciales para casi todas las formas de apoptosis de los metazoos. Sin embargo, no se han encontrado genes que codifiquen caspasas en plantas, levaduras, protozoos y procariotes, organismos en los cuales se han descrito algunas de las características morfológicas típicas de la apoptosis de mamíferos, tales como la condensación de la cromatina, la compactación del citoplasma y el núcleo celular, la ruptura internucleosómica del ADN y la formación de cuerpos apoptósicos (7). En estos organismos, en cambio, se encuentran las metacaspasas, proteínas que fueron identificadas a partir de un análisis de secuencia de genes en busca de moléculas similares a las caspasas $(1,8)$.

Estructuralmente, las metacaspasas son similares a las caspasas en la presencia de la subunidad p20 y de la díada catalítica histidina/ cisteína $(\mathrm{H} / \mathrm{C})$ conservadas en todas las caspasas (figura 1) (1). La composición de aminoácidos de las metacaspasas ha permitido clasificarlas en dos grupos principales: las metacaspasas tipo I, las cuales tienen pro-dominios con motivos repetitivos ricos en prolina y dedos de cinc, y las metacaspasas tipo II, que carecen de pro-dominios pero presentan una inserción de alrededor de 200 aminoácidos en el extremo C-terminal de la subunidad p20 (9).

En forma similar a las caspasas, algunas metacaspasas de plantas, levaduras y parásitos del género Leishmania, requieren de su autoprocesamiento para ser activas enzimáticamente (10-12). Sin embargo, a diferencia de las caspasas que cortan sus substratos después de un residuo aspartato, las metacaspasas lo hacen después de los residuos arginina o lisina $(10,12,13)$. Al parecer, esta especificidad de las metacaspasas está determinada por la presencia de varios residuos aspartato en el sitio catalítico, los cuales favorecen el reconocimiento selectivo de aminoácidos básicos en el substrato (9). El descubrimiento de las metacaspasas en organismos en los cuales no hay genes de caspasas, y sus similitudes con estas últimas, 


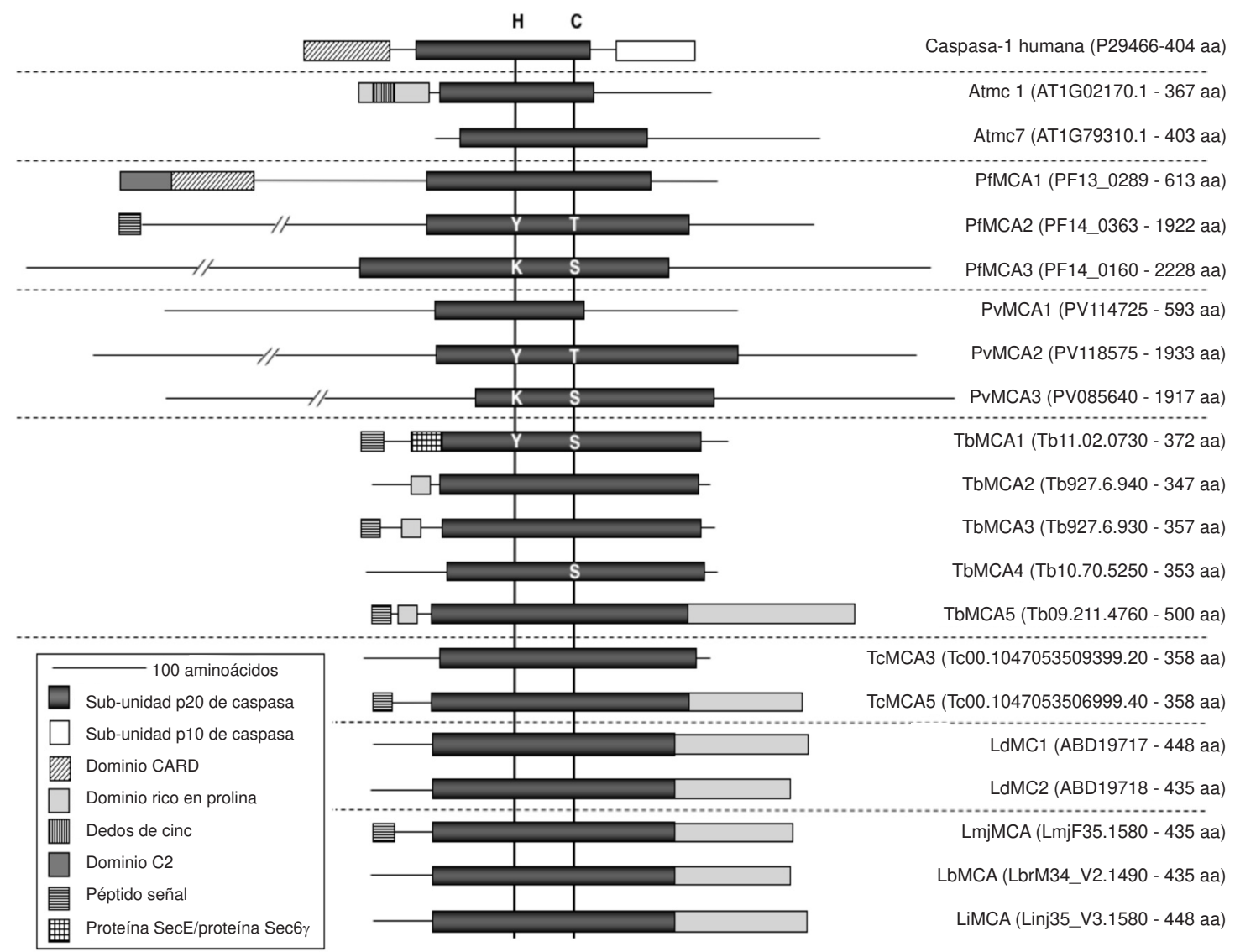

Figura 1. Diagrama esquemático de la estructura de las metacaspasas de parásitos protozoarios humanos. Los dominios constitutivos de las metacaspasas de Plasmodium falciparum (PfMCA1-PfMCA3), Plasmodium vivax (PvMCA1-PvMCA3), Trypanosoma brucei (TbMCA1-TbMCA5), Trypanosoma cruzi (TcMCA3 y TcMCA5), Leishmania donovani (LdMC1 y LdMC2), Leishmania major (LmjMCA), Leishmania braziliensis (LbMCA) y Leishmania infantum (LiMCA), se muestran en comparación con la caspasa-1 humana y dos metacaspasas, una tipo I (Atmc1) y una tipo II (Atmc7), de la planta Arabidopsis thaliana. Entre paréntesis se encuentra la identificación y la longitud en aminoácidos (aa) de cada proteína. Las líneas verticales denotan la posición de la díada catalítica de histidina $(\mathrm{H})$ y cisteína $(\mathrm{C})$. Las substituciones de estos dos aminoácidos por tirosina $(\mathrm{Y})$, treonina $(\mathrm{T})$, lisina $(\mathrm{K})$ y serina $(\mathrm{S})$ están indicadas en las metacaspasas correspondientes. La presencia de algunos dominios proteicos en la estructura de estas metacaspasas, se ha propuesto a partir de sus secuencias de aminoácidos. Dominio CARD: dominio de reclutamiento de caspasas. Dominio C2: módulo de dirección a membranas dependiente de calcio. Péptido señal: secuencia de aminoácidos que define la localización intracelular de proteínas. Proteína SecE/proteína Sec61 $\gamma$ : complejo proteico involucrado en el transporte intracelular de proteínas.

Esta figura está basada en secuencias de aminoácidos de dominio público disponibles en UniProtKB/Swiss-Prot (http://www. expasy.org/sprot/), The Arabidopsis Information Resource (http://www.arabidopsis.org/) y GeneDB (www.genedb.org).

han motivado su estudio con el fin de dilucidar su posible vinculación con procesos apoptósicos en organismos menos evolucionados.

\section{Evaluación de la función biológica de las metacaspasas}

Algunos análisis en diferentes organismos han sugerido que las metacaspasas podrían tener una función similar a la de las caspasas en la muerte celular programada. Por un lado, en la ameba de vida libre Acanthamoeba castellani, se recuperó una metacaspasa de tipo I de una biblioteca de expresión de proteínas de membrana celular implicadas en enquistamiento, un proceso que ha sido considerado como homólogo de la apoptosis (14). 
Por otro lado, en el fitoplancton Emiliana huxleyi, la infección lítica viral aumentó la expresión de la metacaspasa EhMC de manera concomitante con la inducción de la lisis celular, también considerada una forma de muerte celular programada (15). De manera similar, la inducción de especies reactivas de oxígeno en el dinoflagelado marino Pyrocystis lúnula, estimuló la expresión del gen de metacaspasa de manera simultánea con un detrimento de la supervivencia celular (16).

En la levadura Saccharomyces cerevisiae, la proteína codificada por el único gen de metacaspasa presente en su genoma, la YCA1, ha sido implicada en la muerte programada de células envejecidas $(11,17)$ y de células defectuosas en algunas funciones biológicas, como la "deubicuitinación" (18), el recambio de ARNm (19), la replicación de ADN (20) y la regulación de la expresión de genes (21). La YCA1 también se ha asociado con la muerte celular programada de células de levadura expuestas a diferentes tipos de estrés ambiental, como concentraciones tóxicas de peróxido de hidrógeno $\left(\mathrm{H}_{2} \mathrm{O}_{2}\right)$, ácido acético y cloruro de sodio $(11,22,23)$, choque térmico (24), hiperosmosis (25) y toxinas virales (26).

En algunas plantas, las metacaspasas han estado involucradas en muerte celular programada en procesos como la embriogénesis del abeto rojo Picea abies (27) y en la infección por hongos de la planta del tomate (28). Además, se utilizaron células de levadura, en las cuales se había eliminado el gen de la metacaspasa endógena, para demostrar que las metacaspasas Atmc1 (o AtMCP1b) y Atmc4 (o AtMCP2b) de la planta Arabidopsis thaliana cumplían el mismo rol de la YCA1 en la muerte celular programada de levaduras después de la exposición a $\mathrm{H}_{2} \mathrm{O}_{2}(29)$.

En contraste con estos resultados, algunos estudios han demostrado un posible rol de las metacaspasas en la supervivencia de hongos filamentosos. Por ejemplo, células de Aspergillus fumigatus, en las cuales se suprimieron los dos genes de metacaspasas ( $\triangle \operatorname{cas} A / \Delta \operatorname{cas} B)$, no crecieron en presencia de compuestos que alteraban la homeostasis del retículo endoplasmático, lo cual sugiere que estas metacaspasas podrían ser importantes en el crecimiento celular en condiciones de estrés del retículo endoplasmático (30).

\section{Metacaspasas de parásitos protozoarios}

Los parásitos protozoarios humanos de los géneros Plasmodium, Leishmania y Trypanosoma poseen también genes que codifican metacaspasas (1). Estos pueden estar presentes de manera redundante en sus genomas, como sucede en Plasmodium spp. (tres genes por genoma), en Trypanosoma spp. (cinco genes en $T$. brucei y dos genes en $T$. cruzi, uno de ellos en múltiples copias) y en Leishmania donovani (dos genes), o como genes únicos, como sucede en otras especies de Leishmania ( $L$. major, $L$. braziliensis y $L$. infantum) (figura 1).

En Plasmodium spp. sólo se han evaluado hasta el momento las metacaspasas 1 de $P$. falciparum (PfMCA1) y de $P$. berghei, parásito de malaria de roedores, (PbMC1) $(31,32)$. De la metacaspasa PfMCA1 se sabe que, como las caspasas, se autoprocesa y posee un domino de reclutamiento de caspasa, o CARD (caspase recruitment domains), en su porción aminoterminal (31). Por otro lado, parásitos de $P$. berghei en los cuales la secuencia codificadora de PbMC1 fue reemplazada por la proteína verde fluorescente (green fluorescent protein, GFP), permitieron demostrar que la metacaspasa PbMC1 se expresa en gametocitos femeninos y en estadios pre-eritrocíticos, pero no en estadios sanguíneos del parásito, y que la supresión del gen que codifica esta metacaspasa no produce ningún fenotipo especial en los parásitos siendo éstos todavía infectivos (32). A pesar de que no hay información adicional sobre la actividad enzimática y la función biológica de las metacaspasas de Plasmodium spp., se podría especular que la presencia de más de un gen de metacaspasa en estos parásitos garantizaría una redundancia funcional de estas proteínas con la capacidad de que unas puedan reemplazar a otras durante el ciclo de vida de los mismos.

En los parásitos responsables de las leishmaniasis, sólo se han estudiado las metacaspasas de $L$. majory $L$. donovani. La única metacaspasa de $L$. major, LmjMCA, fue expresada en células 
de levadura en las cuales el gen endógeno de metacaspasa había sido suprimido ( $\triangle Y C A 1)$ (12). Tal como se mencionó anteriormente, la presencia del gen YCA1 es necesaria para que suceda la muerte celular programada en las levaduras expuestas a estrés oxidativo (11). Los experimentos con LmjMCA en levadura permitieron demostrar, no sólo que esta metacaspasa cumple el mismo rol que YCA1, sino también, que la LmjMCA se autoprocesa de manera similar a las caspasas. La actividad enzimática de la LmjMCA expresada y purificada de levaduras fue evaluada con substratos sintéticos fluorescentes, con el fin de determinar su especificidad de aminoácido. Estos experimentos permitieron demostrar que esta metacaspasa no tiene actividad de caspasa (no es específica de aspartato), sino que, como las metacaspasas de la planta $A$. Thaliana, la LmjMCA es específica para arginina (12).

Algunos estudios desarrollados en $L$. major han permitido demostrar que la LmjMCA se expresa tanto en promastigotes como en amastigotes y que los intentos dirigidos a la generación de promastigotes con supresión del gen de LmjMCA han sido fallidos lo cual sugiere que este gen es esencial para la supervivencia del parásito (33). La LmjMCA fue localizada en diferentes compartimientos intracelulares del parásito dependiendo de la fase del ciclo celular en el cual se encontraba. Así, por ejemplo, esta proteína se encontró en vesículas citoplasmáticas no identificadas durante la interfase y asociada al cinetoplasto y al núcleo durante la mitosis (33). Además, el extremo $\mathrm{N}$-terminal de LmjMCA posee un péptido señal cuya función de localización mitocondrial fue confirmada por medio de la expresión de este fragmento fusionado con GFP en parásitos. Por otro lado, el aumento de la expresión de LmjMCA en promastigotes de L. major produjo un importante retardo en el crecimiento de los parásitos con defectos en la citocinesis y la generación de parásitos con diferentes ploidías (33). Estos resultados sugieren que la LmjMCA podría tener más de una función en diferentes compartimientos celulares y estar asociada al ciclo celular de los parásitos de L. major, siendo importante tanto en la vida como en la muerte de los mismos.

En $L$. donovani se identificaron dos genes de metacaspasa que codifican dos proteínas que comparten el $96 \%$ de la identidad de la secuencia de aminoácidos (LdMC1 y LdMC2) (13). Ambas se expresan de manera constitutiva; sin embargo, los niveles de expresión de LdMC1 fueron mayores en amastigotes axénicos que en promastigotes. En forma semejante a la LmjMCA, las metacaspasas de $L$. donovani no reconocen substratos sintéticos de caspasas, pero cortan substratos después de los residuos arginina o lisina, actividad que aumenta cuando los parásitos están expuestos a estrés oxidativo. Además, los parásitos en los cuales se indujo la expresión exagerada de estas metacaspasas, fueron significativamente más sensibles a la inducción de la muerte celular programada con $\mathrm{H}_{2} \mathrm{O}_{2}$, en comparación con los parásitos de fenotipo salvaje, lo cual sugiere un posible rol de LdMC1 y LdMC2 en la muerte celular programada de $L$. donovani. A diferencia de LmjMCA, estas metacaspasas no se autoprocesaron, incluso después de la inducción de la muerte celular programada de los parásitos con $\mathrm{H}_{2} \mathrm{O}_{2}$, y se localizaron en vesículas citoplasmáticas correspondientes a los acidocalcisomas del parásito, tanto en promastigotes como en amastigotes axénicos (13).

El genoma de Trypanosoma cruzi, el protozoario causante de la tripanosomiasis americana o enfermedad de Chagas, posee dos genes de metacaspasa: TCMCA3, presente en 16 copias, y TCMCA5, presente como copia única (34). La proteína TcMCA3 se expresa en los cuatro principales estadios del desarrollo del parásito (epimastigotes, tripomastigotes metacíclicos, tripomastigotes celulares y amastigotes), mientras que la TcMCA5 se expresa sólo en epimastigotes (34). Ambas metacaspasas se localizaron en el citoplasma de epimastigotes en cultivo; sin embargo, su translocación hacia el núcleo se detectó luego de la inducción de la muerte celular programada de los parásitos con suero humano fresco, lo cual sugiere una función nuclear. Además, la expresión exagerada de la TcMCA5 en epimastigotes 
produjo un aumento de la sensibilidad de estos parásitos a la inducción de la muerte celular programada con suero humano, al compararse con parásitos que expresaban la proteína en niveles fisiológicos (34). Estos resultados son una evidencia indirecta del posible rol de las metacaspasas de $T$. cruzi en la muerte celular programada. Sin embargo, hasta la fecha no se han publicado hallazgos adicionales con respecto a estas metacaspasas.

Se han descrito cinco genes de metacaspasa en $T$. brucei, el parásito responsable de la tripanosomiasis africana o enfermedad del sueño (35). Una de las primeras aproximaciones en el estudio de la función de las metacaspasas de $T$. brucei fue su expresión en células de levadura, en las cuales el gen endógeno de metacaspasa fue suprimido (36). De las cinco metacaspasas, sólo la metacaspasa 4 (TbMCA4) produjo manifestaciones fenotípicas detectables, como retardo del crecimiento, disfunción mitocondrial y muerte clónica de las levaduras. Al igual que la metacaspasa endógena YCA1, la TbMCA4 también fue localizada en el núcleo de las levaduras, con lo cual los autores de este estudio sugirieron que estas metacaspasas podrían controlar la traducción de genes en el núcleo, afectando la biogénesis de las mitocondrias (36).

Las metacaspasas TbMCA2, TbMCA3 y TbMCA5 también han sido estudiadas en el parásito (37). La expresión de la TbMCA5 se detectó in vitro, tanto en las formas procíclicas como en las formas sanguíneas, mientras que TbMCA2 y TbMCA3 se detectaron solamente en las formas sanguíneas de $T$. brucei. Las tres proteínas estuvieron asociadas de manera parcial a endosomas de reciclaje positivos para la proteína RAB11, los cuales están implicados en la degradación de la glicoproteína variante de superficie, o VSG (variant surface glycoprotein) (37). Con el fin de evaluar su función, la expresión de estas tres metacaspasas fue reducida por medio de la inducción de ARN de interferencia (ARNi) específico para cada gen y eliminada con la generación de parásitos en los cuales los tres genes habían sido suprimidos (37). La inducción de ARNi de manera simultánea para los tres genes produjo defectos en la citocinesis y posterior muerte de los parásitos. Sin embargo, la inducción de ARNi y la supresión de los genes de estas tres metacaspasas de manera secuencial no fueron letales, lo cual sugiere la presencia de mecanismos de adaptación a la falta progresiva de dichas proteínas o la gradual sustitución funcional de las mismas por las otras dos metacaspasas de T. brucei, TbMCA1 y TbMCA4.

La reducción de la expresión de TbMCA2, TbMCA3 y TbMCA5 no afectó la función biológica de los endosomas de reciclaje positivos para RAB11 en los cuales se localizan, lo que indica que estas metacaspasas podrían tener una función asociada a ellos, pero diferente a los procesos de reciclaje conocidos hasta el momento. Con el fin de evaluar el rol de estas tres metacaspasas en la muerte celular programada, los parásitos en los cuales se suprimieron sus respectivos genes, se trataron con prostaglandina D2, conocido inductor de muerte celular programada en $T$. brucei (38). La ausencia simultánea de las tres metacaspasas no tuvo ningún efecto en la tasa de muerte de los parásitos, lo cual sugiere que éstas no participan en los mecanismos de muerte celular programada inducida por prostaglandina D2. Sin embargo, estos resultados no descartan su posible rol en la muerte celular programada inducida por otros mecanismos como el estrés oxidativo, ni el posible reemplazo de su función por parte de TbMCA1 y TbMCA4.

La sustitución natural de aminoácidos en la díada catalítica $\mathrm{H} / \mathrm{C}$ de las metacaspasas TbMCA1 y TbMCA4 (figura 1) ha hecho que éstas se consideren como hipotéticamente inactivas. Sin embargo, la TbMCA4 produjo efectos cuando se expresó en levaduras, tal como se explicó anteriormente, y no hay estudios en los cuales se demuestre la inactividad de estas enzimas. Otras cisteínas presentes en la secuencia de aminoácidos de estas dos metacaspasas podrían reemplazar la función de la cisteína de la díada catalítica, tal como se ha demostrado en la metacaspasa AtMC9 de A. thaliana (39). En AtMC9, el residuo 29 de cisteína reemplaza la función de la cisteína 147 de la díada catalítica cuando esta última se encuentra nitrosilada. $\mathrm{A}$ 
propósito de la actividad enzimática de las cinco metacaspasas de $T$. brucei, sólo se sabe que la TbMCA2 se autoprocesa y es específica de arginina y lisina como otras metacaspasas (40).

\section{Las metacaspasas de parásitos protozoarios como posibles blancos de medicamentos}

Una célula normal no es inmortal y su muerte puede ser inducida por factores externos o formar parte de un proceso fisiológico. Cuando una célula muere como resultado de un cambio ambiental violento, se produce la necrosis, una forma de muerte celular en la cual las células se destruyen, liberan su contenido y provocan una reacción inmunológica a su alrededor (41). Por otro lado, cuando una célula muere como parte de un proceso fisiológico, se produce la muerte celular programada, la cual es ejecutada por procesos activos en los cuales participan proteínas codificadas en el genoma de la célula. La muerte celular programada genera cuerpos apoptósicos que son fagocitados de manera silenciosa por células vecinas, lo cual evita la generación de una respuesta inflamatoria (42).

En los mamíferos, la muerte celular programada conocida como apoptosis, ha sido considerada como un mecanismo para contrarrestar la mitosis, para mantener la homeostasis del número de células durante la embriogénesis y el desarrollo, y para eliminar células con defectos moleculares como lesiones en el ADN (43). A pesar de que el rol de la muerte celular programada en los organismos unicelulares es todavía controversial, se ha sugerido que ésta evolucionó inicialmente en organismos unicelulares como un mecanismo de defensa para mantener la posibilidad de clonación en una población con la selección positiva de microorganismos mejor adaptados al medio, para adaptar el número de microorganismos a los nutrientes disponibles y como un mecanismo de regulación del ciclo y diferenciación celulares (8).

En los parásitos protozoarios humanos, como aquéllos de los cuales se habla en esta revisión, la muerte celular programada se ha postulado como un mecanismo de control de la población de parásitos dentro del insecto vector y dentro de las células hospederas humanas, lo cual favorecería la supervivencia de parásitos infectivos y mejor adaptados $(44,45)$. Algunas características de la muerte celular programada también se han postulado como mediadoras de la evasión de la respuesta inmune, lo que permitiría la fagocitosis silenciosa de los parásitos por las células del sistema monocito-macrofágo humano y favorecería el establecimiento de una infección productiva $(46,47)$. Dado que, al parecer, las metacaspasas hacen parte de los procesos responsables de la muerte celular programada de estos microorganismos, la clara identificación de su función biológica permitirá, no sólo dilucidar la manera en la que ocurre la muerte celular programada en estos organismos, sino, también, la generación de nuevas estrategias terapéuticas dirigidas a eliminar los parásitos por medio de la inducción de la muerte celular programada.

Mucho se ha aprendido respecto a las metacaspasas durante la última década. Sin embargo, su función biológica todavía no es clara en ninguno de los organismos en las cuales se expresan. Se hace evidente la necesidad de desarrollar estudios adicionales dirigidos a conocer los mecanismos de activación e inhibición de estas enzimas. En este sentido, la identificación de proteínas de interacción por medio de métodos como los ensayos de doble híbrido es promisoria. Esta estrategia experimental consistente en la tamización de las posibles interacciones de la proteína de interés con una serie de proteínas derivadas de una biblioteca de ADNc, al ser expresadas de manera simultánea en células de levadura, permitió, por ejemplo, identificar la serpina 1 (Atserpin1) como inhibidor específico de la metacaspasa AtMC9 de la planta $A$. thaliana (48). De igual manera, otras proteínas podrían identificarse como activadoras o como substratos de las metacaspasas, lo cual permitiría esclarecer las cascadas metabólicas y los procesos biológicos en los cuales ellas participan.

En los parásitos causantes de malaria, tripanosomiasis y leishmaniasis, la prioridad es la evaluación de las metacaspasas en sus estadios infecciosos, con el fin de validar estas proteínas como posibles blancos de medicamentos. Si se confirma que las metacaspasas son moléculas efectoras de la muerte celular programada de 
estos microorganismos, deberán desarrollarse mecanismos de activación o de bloqueo de la inhibición endógena de metacaspasas para inducir su muerte celular programada. Si, por el contrario, las metacaspasas son vitales en el desarrollo de los parásitos, la generación de inhibidores específicos permitiría la eliminación de los mismos. La identificación de proteínas de interacción específicas de metacaspasas permitiría en el futuro la generación de substratos o inhibidores sintéticos de las mismas, que podrían ser utilizados como medicamentos.

\section{Agradecimientos}

La autora agradece a Mónica Rengifo por su colaboración en la redacción de esta revisión, a Pedro Romero, por su lectura crítica del texto y a Nicolas Fasel, por todo el apoyo brindado.

\section{Conflictos de intereses}

La autora declara no incurrir en ningún conflicto de interés mediante la publicación de esta revisión de tema.

\section{Financiación}

\section{Universidad de Lausana, Suiza.}

\section{Referencias}

1. Uren AG, O'Rourke K, Aravind LA, Pisabarro MT, Seshagiri S, Koonin EV, et al. Identification of paracaspases and metacaspases: two ancient families of caspase-like proteins, one of which plays a key role in MALT lymphoma. Mol Cell. 2000;6:961-7.

2. Lavrik IN, Golks A, Krammer PH. Caspases: pharmacological manipulation of cell death. J Clin Invest. 2005;115:2665-72.

3. Riedl SJ, Shi Y. Molecular mechanisms of caspase regulation during apoptosis. Nat Rev Mol Cell Biol. 2004;5:897-907.

4. MacFarlane M, Williams AC. Apoptosis and disease: a life or death decision. EMBO Rep. 2004;5:674-8.

5. Yuan J, Shaham S, Ledoux S, Ellis HM, Horvitz HR. The $C$. elegans cell death gene Ced-3 encodes a protein similar to mammalian interleukin-1 $\beta$-converting enzyme. Cell. 1993;75:641-52.

6. Kumar S, Doumanis J. The fly caspases. Cell Death Differ. 2000;7:1039-44.

7. Debrabant A, Lee N, Bertholet S, Duncan R, Nakhasi HL. Programmed cell death in trypanosomatids and other unicellular organisms. Int J Parasitol. 2003;33:257-67.
8. Koonin EV, Aravind L. Origin and evolution of eukaryotic apoptosis: the bacterial connection. Cell Death Differ. 2002;9:394-404.

9. Vercammen D, Declercq W, Vandenabeele P, van Breusegem F. Are metacaspases caspases? J Cell Biol. 2007;179:375-80.

10. Vercammen D, van de Cotte B, De Jaeger G, Eeckhout D, Casteels P, Vandepoele K, et al. Type II metacaspases Atmc4 and Atmc9 of Arabidopsis thaliana cleave substrates after arginine and lysine. J Biol Chem. 2004;279:45329-36.

11. Madeo F, Herker E, Maldener C, Wissing S, Lachelt S, Herlan M, et al. A caspase-related protease regulates apoptosis in yeast. Mol Cell. 2002;9:911-7.

12. González IJ, Desponds C, Schaff C, Mottram JC, Fasel $\mathbf{N}$. Leishmania major metacaspase can replace yeast metacaspase in programmed cell death and has arginine-specific cysteine peptidase activity. Int $\mathrm{J}$ Parasitol. 2007;37:161-72.

13. Lee N, Gannavaram S, Selvapandiyan A, Debrabant A. Characterization of metacaspases with trypsin-like activity and their putative role in the programmed cell death in the protozoan parasite Leishmania. Eukaryot Cell. 2007;6:1745-57.

14. Trzyna WC, Legras XD, Cordingley JS. A type-1 metacaspase from Acanthamoeba castellanii. Microbiol Res. 2008;163:414-23.

15. Bidle KD, Haramaty L, Barcelos E Ramos J, Falkowski P. Viral activation and recruitment of metacaspases in the unicellular coccolithophore, Emiliania huxleyi. Proc Natl Acad Sci USA. 2007;104:6049-54.

16. Okamoto OK, Hastings JW. Genome-wide analysis of redox-regulated genes in a dinoflagellate. Gene. 2003;321:73-81.

17. Herker E, Jungwirth H, Lehmann KA, Maldener C, Frohlich KU, Wissing S, et al. Chronological aging leads to apoptosis in yeast. J Cell Biol. 2004;164:501-7.

18. Bettiga M, Calzari L, Orlandi I, Alberghina L, Vai M. Involvement of the yeast metacaspase Yca1 in ubp10Delta-programmed cell death. FEMS Yeast Res. 2004;5:141-7.

19. Mazzoni C, Herker E, Palermo V, Jungwirth $H$, Eisenberg $T$, Madeo F, et al. Yeast caspase 1 links messenger RNA stability to apoptosis in yeast. EMBO Rep. 2005;6:1076-81.

20. Weinberger M, Ramachandran L, Feng L, Sharma K, Sun X, Marchetti M, et al. Apoptosis in budding yeast caused by defects in initiation of DNA replication. J Cell Sci. 2005;118:3543-53.

21. Mitsui K, Nakagawa D, Nakamura M, Okamoto T, Tsurugi K. Valproic acid induces apoptosis dependent of Yca1p at concentrations that mildly affect the proliferation of yeast. FEBS Lett. 2005;579:723-7. 
22. Khan MA, Chock PB, Stadtman ER. Knockout of caspase-like gene, YCA1, abrogates apoptosis and elevates oxidized proteins in Saccharomyces cerevisiae. Proc Natl Acad Sci USA. 2005;102:17326-31.

23. Wadskog I, Maldener C, Proksch A, Madeo F, Adler L. Yeast lacking the SRO7/SOP1-encoded tumor suppressor homologue show increased susceptibility to apoptosis-like cell death on exposure to $\mathrm{NaCl}$ stress. Mol Biol Cell. 2004;15:1436-44.

24. Flower TR, Chesnokova LS, Froelich CA, Dixon C, Witt SN. Heat shock prevents alpha-synuclein-induced apoptosis in a yeast model of Parkinson's disease. J Mol Biol. 2005;351:1081-100.

25. Silva RD, Sotoca R, Johansson B, Ludovico P, Sansonetty F, Silva MT, et al. Hyperosmotic stress induces metacaspase- and mitochondria-dependent apoptosis in Saccharomyces cerevisiae. Mol Microbiol. 2005;58:824-34

26. Ivanovska I, Hardwick JM. Viruses activate a genetically conserved cell death pathway in a unicellular organism. J Cell Biol. 2005;170:391-9.

27. Suarez MF, Filonova LH, Smertenko A, Savenkov EI, Clapham DH, von Arnold S, et al. Metacaspasedependent programmed cell death is essential for plant embryogenesis. Curr Biol. 2004;14:R339-40.

28. Hoeberichts FA, ten Have A, Woltering EJ. A tomato metacaspase gene is upregulated during programmed cell death in Botrytis cinerea-infected leaves. Planta. 2003;217:517-22.

29. Watanabe N, Lam E. Two Arabidopsis metacaspases AtMCP $1 b$ and AtMCP2b are arginine/lysine-specific cysteine proteases and activate apoptosis-like cell death in yeast. J Biol Chem. 2005;280:14691-9.

30. Richie DL, Miley MD, Bhabhra R, Robson GD, Rhodes JC, Askew DS. The Aspergillus fumigatus metacaspases CasA and CasB facilitate growth under conditions of endoplasmic reticulum stress. Mol Microbiol. 2007;63:591-604.

31. Meslin B, Barnadas C, Boni V, Latour C, De Monbrison F, Kaiser K, et al. Features of apoptosis in Plasmodium falciparum erythrocytic stage through a putative role of PfMCA1 metacaspase-like protein. $J$ Infect Dis. 2007;195:1852-9.

32. Le Chat L, Sinden RE, Dessens JT. The role of metacaspase 1 in Plasmodium berghei development and apoptosis. Mol Biochem Parasitol. 2007;153:41-7.

33. Ambit A, Fasel N, Coombs GH, Mottram JC. An essential role for the Leishmania major metacaspase in cell cycle progression. Cell Death Differ. 2008;15:113-22.

34. Kosec G, Álvarez VE, Aguero F, Sánchez D, Dolinar M, Turk V, et al. Metacaspases of Trypanosoma cruzi: possible candidates for programmed cell death mediators. Mol Biochem Parasitol. 2006;145:18-28.
35. Mottram JC, Helms MJ, Coombs GH, Sajid M. Clan CD cysteine peptidases of parasitic protozoa. Trends Parasitol. 2003;19:182-7.

36. Szallies A, Kubata BK, Duszenko M. A metacaspase of Trypanosoma brucei causes loss of respiration competence and clonal death in the yeast Saccharomyces cerevisiae. FEBS Lett. 2002;517:144-50.

37. Helms MJ, Ambit A, Appleton P, Tetley L, Coombs GH, Mottram JC. Bloodstream form Trypanosoma bruce depend upon multiple metacaspases associated with RAB11-positive endosomes. J Cell Sci. 2006;119:110517.

38. Figarella K, Rawer M, Uzcategui N L, Kubata BK, Lauber K, Madeo F, et al. Prostaglandin D2 induces programmed cell death in Trypanosoma brucei bloodstream form. Cell Death Differ. 2005;12:335-46.

39. Belenghi B, Romero-Puertas MC, Vercammen $\mathrm{D}$, Brackenier $\mathrm{A}$, Inze $\mathrm{D}$, Delledonne $\mathrm{M}$, et al. Metacaspase activity of Arabidopsis thaliana is regulated by S-nitrosylation of a critical cysteine residue. J Biol Chem. 2007;282:1352-8.

40. Moss CX, Westrop GD, Juliano L, Coombs GH, Mottram JC. Metacaspase 2 of Trypanosoma brucei is a calcium-dependent cysteine peptidase active without processing. FEBS Lett. 2007;581:5635-9.

41. Jäättelä M. Programmed cell death: many ways for cells to die decently. Ann Med. 2002;34:480-8.

42. Bursch W. Multiple cell death programs: Charon's lifts to Hades. FEMS Yeast Res. 2004;5:101-10.

43. Vaux DL, Strasser A. The molecular biology of apoptosis. Proc Natl Acad Sci USA. 1996;93:2239-44.

44. Lee N, Bertholet S, Debrabant A, Muller J, Duncan R, Nakhasi HL. Programmed cell death in the unicellular protozoan parasite Leishmania. Cell Death Differ. 2002;9:53-64

45. Lindoso JA, Cotrim PC, Goto H. Apoptosis of Leishmania (Leishmania) chagasi amastigotes in hamsters infected with visceral leishmaniasis. Int J Parasitol. 2004;34:1-4.

46. Wanderley JL, Benjamin A, Real F, Bonomo A, Moreira ME, Barcinski MA. Apoptotic mimicry: an altruistic behavior in host/Leishmania interplay. Braz J Med Biol Res. 2005;38:807-12.

47. van Zandbergen G, Bollinger A, Wenzel A, Kamhawi $\mathbf{S}$, Voll R, Klinger $\mathbf{M}$, et al. Leishmania disease development depends on the presence of apoptotic promastigotes in the virulent inoculum. Proc Natl Acad Sci USA. 2006;103:13837-42.

48. Vercammen D, Belenghi B, van de Cotte B, Beunens T, Gavigan JA, De Rycke R, et al. Serpin1 of Arabidopsis thaliana is a suicide inhibitor for metacaspase 9 . J Mol Biol. 2006;364:625-36. 